\title{
Coal Technology Program Progress Report for January 1976
}

\section{OAK RIDGE NATIONAL LABORATORY}




\section{DISCLAIMER}

This report was prepared as an account of work sponsored by an agency of the United States Government. Neither the United States Government nor any agency Thereof, nor any of their employees, makes any warranty, express or implied, or assumes any legal liability or responsibility for the accuracy, completeness, or usefulness of any information, apparatus, product, or process disclosed, or represents that its use would not infringe privately owned rights. Reference herein to any specific commercial product, process, or service by trade name, trademark, manufacturer, or otherwise does not necessarily constitute or imply its endorsement, recommendation, or favoring by the United States Government or any agency thereof. The views and opinions of authors expressed herein do not necessarily state or reflect those of the United States Government or any agency thereof. 


\section{DISCLAIMER}

Portions of this document may be illegible in electronic image products. Images are produced from the best available original document. 
Printed in the United States of America: Available from National Technical Information Service

U.S. Department of Commerce

5285 Port Royal Road, Springtield, Virginia 22161

Price: Printed Copy $\$ 4.00$; Microfiche $\$ 2.25$

This report was prepared as an account of work sponsored by the United States Government. Neither the United States nor the Energy Research and Development Administration, nor any of their employees, nor any of their contractors, subcontractors, or their employees, makes any warranty, express or implied, or assumes any legal liability or responsibility for the accuracy, completeness or usefulness of any information, apparatus, product or process disclosed, or represents that its use would not infringe privately owned rights. 
Contract No. W-7405-eng-26

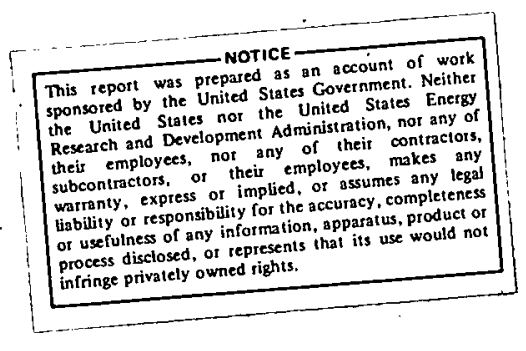

COAL TECHNOLOGY PROGRAM

PROGRESS REPORT FOR JANUARY 1976

\section{MARCH 1976}

NOTICE This document contains information of a preliminary nature and was prepared primarily for internal use at the Oak Ridge National Loboratory. It is gubjoot to rovicion or correction and therefore does not represent a final report.

OAK RIDGE NATIONAL IABORATORY

Oak Ridge, Tennessee 37830 operated by

UNION CARBIDE CORPORATION

for the

TNITGY REETARCH AND DEVELOFMENT ADMINISTRATION 
Abstract ......................... . . 1

1. Summary . . . . . . . . . . . . . . . . . . 2

2. Hydrocarbonization Research . . . . . . . . . . . . . 3

2.1 Experimental Development . . . . . . . . . . . 3

2.2 Bench-Scale System . . . . . . . . . . . . . . 5

2.3 Residua Carbonization . . . . . . . . . . . . . . 7

2.4 References for Sect. 2.............. 8

3. Supporting Research and Development in Separations Technology . . 8

3.1 Additive Agglomeration Studies: Laboratory-Scale . . . . 8

3.2 Additive Agglomeration Studies: Bench-Scale . . . . . . 9

3.3 References for sect. 3 . . . . . . . . . . . . 9

4. Engineering Evaluations of Nuclear Process Heat

for Coal Conversion . . . . . . . . . . . . . . . 10

5. Analytical Chemistry . . . . . . . . . . . . . . . 10

5.I Analyses of Aqueous By-Products from Fossil

Fuel Conversion Process .. . . . . . . . . . . . 11

5.2 Separation of Sulfur and Nitrogen Classes

of Compounds from Complex Mixtures . . . . . . . . . 12

5.3 Plant Microcosm Exposure Studies with

Simulated Stack Gas Emissions . . . . . . . . . . . 13

5.4 Coal and Fly Ash Analysis by a Modified

Multielement Isotope Dilution SSMS Technique . . . . . . 13

5.5 Analytical Services ............... . 14

6. Engineering Evaluations of the Synthoil

and Hydrocarbonization Processes . . . . . . . . . . 15

6.1 Synthoil Process ................. 15

6.2 Hydrocarbonization Frocess ............. 16

\% Coal-Hueled MLUS . . . . . . . . . . . . . . . . 18

8. Experimental Engineering Support of an

In Situ Gasification Process . . . . . . . . . . . . 20

8. I Large-Block Pyrolysis Studies . . . . . . . . . . . 20

8.2 Coal-derived Aerosols: Disengagement Techniques . . . . 20 


\section{COAL TECHNOLOGY PROGRAM PROGRESS REPORT FOR JANUARY 1976}

\section{ABSTRACT}

This report - the eighteenth of a series - is a compendium of monthly progress reports for the ORNL research and development projects that are in support of the increased utilization of coal as a source of clean energy. The projects reported this month include those for hydrocarbonization research, solid-liquid separations, engineering evaluations of nuclear process heat for coal conversion, analytical chemistry, engineering evaluations of the Synthoil and Hydrocarbonization processes, coal-fueled MIUS, and experimental engineering support of an in situ gasification process.

\section{SUMMARY}

J. P. Nichols

Highlights of our progress in January are summarized below:

- Most of the effort during this month in hydrocarbonization research has dealt with several needed modifications to equipment. A run with the atmospheric pressure hydrocarbonizer containing an axial draft tube to induce solids recirculation was completed successfully. The liquid yields from this run appeared to be substantially greater than in previous runs without the draft tube. Coal feeding problems hampered three attempts to operate the bench-scale system and corrective actions are underway.

- Additive agglomeration tests in supporting research and development in separations technology have continued to show that a commercial additive from Tretolite will significantly improve settling rates of solids in Solvent Refined Coal Unfiltered OII (SRC-UFO). Some success has been obtained with inorganic additives, and it has been decided to continue these studies as a small scale effort. It is believed that investigation of these cationic/anionic inorganic materials will contribute to the understanding of agglomeration in heavy organic mixtures such as coalderived liquids.

- In engineering evaluations of nuclear process heat for coal conversion, two draft reports from United Engineers were reviewed "Evaluation of a Coal Liquefaction Process Using Either a Nuclear or Fossil Heat Source" and "An Evaluation of Pollution and Water Consumption Related to Selected Coal Conversion Processes" - and after comments by us will constitute a portion of our report to Fossil Energy on the application of nuclear process heat to coal conversion. 
- In analytical chemistry, aqueous by-products from the Synthane gasification process and simulated in-situ oil shale retorting are being analyzed for organic content. Also, preparations are being made to commence a plant microcosm exposure study with simulated stack gas emissions.

- In the engineering evaluations work for synthoil, cost.s were obtained for most equipment items in the coal preparation section. The flowsheet and overall material balance for a combined centrifugationfiltration plant were completed. Compilation of utilities requirements for the overall facility indicate that a low-Btu gas production facility using additional fresh coal will be required. For Hydrocarbonization, the design and cost estimate for the coal beneficiation system and cost estimate for the hydrogen plant were received. A preliminary t'lowsheet and a layout plan for coal and limestone preparation were prepared.

- The detailed design effort of Phase III and the preparation nf $A$. bid package for procurement of the fluidized bed furnace in the coal-fueled MIUS program continues. An initial mixing test of coal injected into a fluidized bed was completed in the cold flow model and development of the vibrator-eductor coal feed system continued.

- In experimental engineering support of an in situ gasification process, scouting studies defining the effectiveness of aerosol disengagement techniques were continued. Electrostatic precipitation and packed tower scrubbing were examined, and only packed tower scrubbing appeared to be completely effective. 


\section{HYDROCARBONIZATION RESEARCH}

H. D. Cochran, Jr.

Summary

During January, the Lucite model of the recirculating fluidized bed reactor was used to help solve problems encountered in the atmospheric pressure hydrocarbonizer. A run with the atmospheric pressure hydrocarbonizer containing an axial draft tube to induce solids recirculation was completed successfully. The liquid yields from this run appeared to be substantially greater than in previous runs without the draft tube. Reduced cracking of volatilized liquids in the reactor is the postulated reason for increased liquid recovery. Coal feeding problems hampered three attempts to operate the bench-scale system during the month. It is believed that the problems are understood, and corrective actions have been taken.

\subsection{Experimental Development.}

P. R. Westmoreland, J. B. Gibson, R. L. Andrews, and J. C. Rose

Ambient mock-ups

Ambient studies with the 4-in.-ID recirculating fluidized bed have made significant contributions to the experimental program. Run AHC-1O (discussed below) was marked by excessive solids carryover, by difficulty in setting gas flows to cause solids recirculation, and by difficulty in determining whether recirculation was occurring.

Although part of the solids carryover in Run AHC-10 resulted from an unusually high fines content, the reactor geometry was also important. Mock-up tests using char from Run AHC-9 (3.4 wt \% less than. 200 mesh) indicated that the coal plume above the draft tube exceeded 12 in. throughout the optimal range of operation, resulting in substantial solids carryover. Reducing the draft tube length from 33 in. to $241 / 4 \mathrm{in}$. ( 1 1/2 in. above the char withdrawal pipe) and addition of a solids deflector sharply decreased carryover. These modifications were duplicated on the atmospheric hydrocarbonizer.

Coal prepared for Run AHC-11 was tested in the mock-up to establish gas flow settings for stable operations. Stable recirculation occurs only within an envelope of flow settings. Using the minimum fluidization flows calculated by the correlation of Wen and $\mathrm{Yu}^{\mathrm{l}}$ with minimum entrained flow for the draft tube approximated according to Kunii and Levenspiel, 2 feed rates were predicted which fit within the envelope of stable recirculation. Ambient mock-up tests of the coal prepared for Run AHC-II confirmed stable recirculation at the calculated gas feed rates, so the correlations were extended to the high-temperature hydrogen operation for Run AHC-II. 
Characterization of solid recirculation performance in Lucite models will be continued as necessary in support of recirculating fluidized-bed operation.

\section{High-temperature studies}

Two recirculating fluidized bed experiments were attempted in the atmospheric pressure reactor. Run AHC-10 was terminated because of a plugged line. In the next attempt, Run AHC-11, smooth batch operation of recirculating fluidized-bed hydrocarbonization was achieved. A final carbon balance on Run AHC-8 showed 100.2\% carbon recovery, and a preliminary balance on Run AHC-9 was determined.

Upon installation of the draft tube reactor. Run AHC-10 was atterupted using argon for carbonization at $1060^{\circ} \mathrm{F}$. Over $25 \mathrm{~g}$ of coal fines were blown out of the reactor during start up. (Excessive fines, about 13 wt $\%$, resulted from inadequate sieving of the feed.) Bed pressure drop data could not be interpreted as to whether recirculation was taking place. Run AHC-1O was aborted about 25 min into the run because of a $25-\mathrm{g}$ plug in the cyclone-to-condenser line. As described above, later experiments using ambient mock-ups proved that this carryover resulted both from fines content and from a long draft tube.

Results from mock-up testing contributed to successful operation in a second atmospheric hydrocarbonization experiment with the recirculating fluidized bed, Run AHC-1工. Maximum temperature was $1020^{\circ} \mathrm{F}$, and hydrogen was used as the fluidizing gas. The yield of liquids and tar from Run AHC-Il appeared to be substantially greater than in earlier runs without the draft tube, c.f. Runs AHC-8 and AHC-9. It is postulated that, as a result of the substantially reduced vapor residence time in the reactor with the draf't tube installed, thermal cracking of the Iiquid products is reduced and greater recoveries may be achieved.

Final analysis results from Run AHC-8 (batch fluidized-bed hydrocarbonization to $1060^{\circ} \mathrm{F}$ ) indicated $100.0 \%$ recovery of carbon, with $13.2 \%$ gas yield of the carbon and with $12.2 \%$ liquid yield. A preliminary carbon balance on Run AHC-9 (batch fluidized-bed hydrocarbonization to $1000^{\circ} \mathrm{F}$ ) gives only $89.3 \%$ recovery. Solids and tar were not recovered from the cyclone-to-condenser line. Gas yield was $12.5 \%$ and liquid yield was $11.1 \%$, suggesting that char recovery may have been incomplete.

No further atmospheric pressure hydrocarbonization experiments are planned although the equipment, as modified for residua carbonization, is suitable for turther experiments should they be necessary. Carbon balances and yield data from Runs AHC-9 and AHC-17 will be reported when completed, and a final, summary report of the atmospheric pressure hydrocarbonization experiments will be included in a later progress report. 


\subsection{Bench-Scale System}

H. D. Cochran, Jr., and G. L. Yoder

Design and review

Preliminary design of modifications to the bench-scale system. necessary to raise its pressure capability from 20 to 80 atm is underway. Three major modifications will be required:

(1) A booster compressor for hydrogen having the following specifications is required: suction pressure 300 to 1250 psig, discharge pressure $1250 \mathrm{psig}$, capacity $70 \mathrm{scfm}$. At present it appears that an oil- and water-free, air-driven, nonlubricated compressor is the optimum choice. Detailed specifications are being prepared for bids.

(2) At $80 \mathrm{~atm}$ the present preheater has a maximum wall temperature of $1050^{\circ} \mathrm{F}$. Consequently, for operation at 80 atm and $1250^{\circ} \mathrm{F}$, additional preheat will be required.

(3) The reactor; presently rated for $20 \mathrm{~atm}$ at $1250^{\circ} \mathrm{F}$, will have to be replaced.

For safety reasons, the 80-atm system will be limited to a hydrogen inventory of $s 260 \mathrm{ft}^{3}$. STP and a hydrogen supply rate of $570 \mathrm{scfm}$. It is also necessary to have a coal feed rate of $10 \mathrm{lb} / \mathrm{hr}$ and a solids residence time on the order of $30 \mathrm{~min}$. For fluidization of the solid with $\leq 70$ scfm of hydrogen in a bed having a solids residence time of about $30 \mathrm{~min}$ at about $10 \mathrm{lb} / \mathrm{hr}$ feed rate, some compromise on reactor inside diameter and height is necessary. A 2.5-in.-ID reactor appears to be the best compromise. Larger reactor diameters with reasonable particle size require more gas for fluidization. Smaller reactor diameters require excessive reactor height to attain the desired solids residence time.

Initial design efforts have focused on an integral reactor-preheater with the following characteristics: (1) a cold wall outer shell for pressure containment, (2) insulated internally from (3) internal heaters, and (4) a 2.5-in. -ID reactor core. Design difficulties, as yet unresolved, are associated with the flanged end closures and the inlet and outlet nozzles which are complicated by thermal expansion.

Bids will be solicited for the hydrogen booster compressor, and a detalled design of the integral reactor-preheater will be prepared for preliminary review. 
Fabrication and installation

Several subsystems for the bench-scale hydrocarbonizer were completed as follows: the hydrogen supply station was completed and gas supply valving was connected. Combustible gas monitors and hydrogen detectors in the process area were tied into the control panel. The oxygen analyzer in the process gas line (to verify purging before hydrogen introduction) was tied into the control panel. Heated lines between the preheater and reactor and between the reactor and scrubber were insulated. The heat exchangers on the scrubber were cleaned and reinstalled.

No effort is planned in this area except maintenance as required.

\section{Operatizon}

Continued difficulties in feeding coal to the reactor have frustrated plans for operation during January. It is believed that the problems are understood, and corrective actions are underway.

In attempts to prepare and feed coal meeting the feeder design specifications, -50 by +150 mesh, excessive fines $(\sim 20$ wt $\%<10 \mu$ ) caused the coal to lose its free-flowing characteristics, and bridging was experienced in the feed hopper above the coal feeder. The fines are difficult to remove by screening; holdup times of 0.5 to $1.0 \mathrm{hr}$ on the screen are required. Facilities for air classification, to elutriate fines before screening, are not presently available to this project.

As an interim solution to this problem, coal screened to -20 by +50 mesh $(\sim 2$ wt $\%<10 \mu)$ was fed to the reactor in three attempts to run under reactor conditions of $20 \mathrm{~atm}$ and $1200^{\circ} \mathrm{F}$ with nitrogen. Although it was possible to feed for short periods of time, saltation of larger particles in the pneumatic transport line repeatedly plugged the line.

Three actions have been taken to overcome these problems:

(1) Approximately 1 ton of Wyodak coal was shipped to Morgantown Energy Research Center (MERC) for grinding and classification to -50 by +150 mesh specifications. This material should be available within a few weeks to sustain our operation tor about 5 runs.

(2) Ca a oupply controla for the pneimatice tranoport of coal have been modified to permit sustained pneumatic transport of -20 . mesh coal.

(3) A 5-1b batch of carefully screened -50 by +150 mesh coal ( 2 wt \% $<10 \mu$ ) has been prepared to demonstrate that coal which meets feeder design specifications can be fed successfully. 
Operations are presently delayed for the following safety-related shakedown tests which are now in progress: (1) leak test of the hydrogen supply station, (2) witnessed pressurization test of the bench-scale system at design temperature to pressure 1.15 times design pressure, (3) DOP test of in-line filter to assure $99 \%$ removal efficiency for $0.3 \mu$ particulates, (4) smoke generator verification of airflow in process room, and (5) proof testing of the emergency shutdown system.

Four runs are planned for February as follows: (I) demonstrate feeding of $5 \mathrm{lb}$ of -50 by +150 mesh coal to reactor at $20 \mathrm{~atm}$ and $1200^{\circ} \mathrm{F}$ with nitrogen, (2) feed approximately $50 \mathrm{lb}$ of -20 by +50 mesh coal to reactor at $20 \mathrm{~atm}$ and $1200^{\circ} \mathrm{F}$ for material balance with nitrogen, (3) feed approximately $100 \mathrm{lb}$ of -50 by +150 mesh coal (if available from MERC) to reactor at $20 \mathrm{~atm}$ and $1200^{\circ} \mathrm{F}$ with nitrogen, and (4) feed approximately $100 \mathrm{lb}$ of -50 by +150 mesh coal to reactor at 5 atm and $1050^{\circ} \mathrm{F}$ with hydrogen if (3) is successful.

\subsection{Residua Carbonization}

H. D. Cochran, Jr., and J. B. Gibson

Two runs with coal were attempted in the residua carbonizer during January. In the first run severe problems were experienced with carryover of coal particles from the reactor to the condenser which resulted in plugging of a line and termination of the experiment. Ambient studies were conducted with a Lucite model of the reactor and draft tube to provide a better understanding of the carryover problem. As a result of these studies, the draft tube was reduced in Iength from 33 in. to $24 \mathrm{in}$. and a cup-shaped deflector was added $9 \mathrm{in}$. above the top of the draft tube. As a result of these changes, carryover was greatly reduced in the second run which was completed successfully. More information on these runs is given separately in the report on the Hydrocarbonization project.

The feed system and char receiver were fabricated this month, and installation of these vessels will begin shortly. In preparation for feeding studies, we have begun grinding residua. The heat generated by the grinding operation tended to make the particles of residua agglomerate. Mixing dry ice with the residua in the grinder alleviated the sticking problem.

The first draft of the review and evaluation of the CSF carbonizer has been completed. The draft has undergone internal review and is now being revised.

The revised draft of the review and evaluation will be completed this month and will be distributed for comments. Installation of the feed vessel and char receiver will be completed and shakedown of the feeding system will begin. If the feeding system performs adequately, 
the first experiment with residuum will be attempted; otherwise, one additional experiment with coal will be made while feeding problems are resolved.

\subsection{References for sect. 2}

1. C. Y. Wen and Y. H. Yu, A.I.Ch.E. Journal 12, 610 (May 1966).

2. D. Kunii and O. Levenspiel, Fluidization Engineering, New York, John Wiley \& Sons, 1969, p. 78.

\section{SUFFORTING REEEARCH $\Lambda$ NID DEVELOPMENT' \\ IN SEPARATIONS TECHNOLOCY}

B. R. Rodgers

Summary

Additive agglomeration tests have continued to show that a commercial additive from Tretolite will significantly improve settling rates of solids in Solvent Refined Coal Unfiltered Oil (SRC-UFO). Discrepancies were noted between the bench-scale and laboratory-scale results; namely, longer settling times were required on the bench-scale apparatus to produce a given clarity of upper phase. Some success has been obtained this month with inorganic additives, and it has been decided to continue these studies as a small scale effort. It is believed that investigation of these cationic/anionic inorganic materials will contribute to the understanding of agglomeration in heavy organic mixtures such as coal-derived liquids.

\subsection{Additive Agglomeration Studies: Laboratory-Scale}

S. Katz and B. R. Rodgers

Agglomeration-settling tests have continued using the laboratoryscale test system and procedures described elsewhere. 1 Previously, series

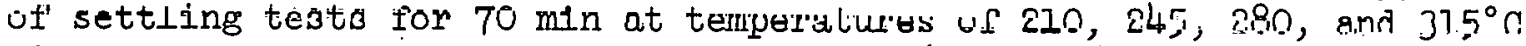
with $0,250,500$, and $1000 \mathrm{ppm}$ of additive (petroleum type additive from Tretolite) indicated that better settling occurred at higher temperatures and additive concentrations. ${ }^{2}$ However, systematic variations in the ash values resulted; notably, the ash values were either consistently high or consistently low for all tests performed on a particular day. This indicated that the ash content of the starting material might have varied from day to day; possibly due to settling in the storage container. To eliminate the possibility that inadequate mixing of the starting UFO contributed to the observed variations, more vigorous premixing was used 
for the test series described below. To reduce other systematic errors, a sedimentation run with UFO only was made just before a run with additive; this allowed direct comparisons at the same conditions. The tests indicate that significant settling can be achieved in less than $30 \mathrm{~min}$ (the ash content of the upper $30 \%$ fraction was less than $0.15 \%)$. The efficacy of the Tretolite additive for improving agglomeration is verified by these results.

The effectiveness of various additive materials such as the Tretolite additive, improvements in testing techniques, and consideration of possible agglomeration or recrystallization mechanisms has stimulated reevaluation of previous studies of inorganic additives. An additional screening test using 80-200 mesh silica gel at a concentration of $4000 \mathrm{ppm}$ showed no improvement in settling rates. Other inorganic materials are under evaluation. A literature search will be made of other materials which are compatible with coal liquefaction liquids.

\subsection{Additive Agglomeration Studies: Bench-Scale}

B. R. Rodgers, S. Katz, and D. A. McWhirter

Initial results indicate that longer settling times may be required to produce a given clarity of overflow for the bench-scale apparatus compared to the laboratory-scale apparatus. Nine runs this month at temperatures from 390 to $600^{\circ} \mathrm{F}$, and Tretolite additive concentrations from 1500 to $4000 \mathrm{ppm}$, have shown that $100 \mathrm{~min}$ is required to obtain a $30 \%$ upper phase which meets EPA standards for SRC product. While this time is not excessive for a settling operation, it is considerably longer than the 30 min required to obtain this clarity using the laboratoryapparatus. Reasons for the discrepancies are under study.

\subsection{References for sect. 3}

1. J. P. Nichols (Program Director), Coal Technology Program Quarterly Progress Report for the Period Ending September 30, 1975, ORNL-5093 (December 1975).

2. J. P. Nichols (Program Director), Coal Technology Program Quarterly Progress Report for the Period Ending December 31, 1975, ORNL-5120 (in publication). 
4. ENGINEERLNG EVALUATIONS OF NUCLEAR PROCESS

HEAT FOR COAL CONVERSION

W. R. Gambill

Second drafts of two reports were received from United Engineers. These reports, titled "Evaluation of a Coal Liquefaction Process Using Either a Nuclear or Fossil Heat Source" and "An Evaluation of Pollution and Water Consumption Related to Selected Coal Conversion Processes" will, after final comment by us, constitute a portion of our February report to Fossil Energy on the application of nuclear process heat to coal conversiun. Other sectiono of the rcport will address a VHTR-driven dirert. steam/coal gasification plant (for which a revised block diagram has been prepared and cost estimates are being made); external hydrogen supply from a thermochemical water splitting unlt to prucesses cunverting coal to methanol, syncrude, SNG, and gasoline; and a review of materials problems related to He-heated process heat exchangers for reforming, coal gasification, and thermochemical hydrogen production.

E. Clark, Chief of gasification programs (DCCU), in a meeting with I. Spiewak and W. R. Gambill in Washington on January 13, indicated that support for this evaluation study would be continued at a level of $\$ 125,000$ for the period January through September 1976 - i. e., through the transition quarter. A revised work statement reflecting the priorities established at the meeting has been transmitted to Mayo Carrington. . 


\section{ANALYTICAL CHEMISTRY}

W. D. Shults

$\underline{\text { Summary }}$

Aqueous by-products from the Synthane gasification process and simulated in-situ oil shale retorting are being analyzed for organic content. Organic concentrates are being prepared by different methods for comparison of overall and class extraction efficiencies. A method for producing concentrates of the nitrogen and sulfur containing classes of compounds is being investigated. Preparations are being made to commence a plant microcosm exposure study with simulated stack gas emissions.

\subsection{Analyses of Aqueous By-Products from Fossil Fuel Conversion Process}

B. R. Clark, M. R. Guerin, C. H. Ho, and I. B. Rubin

Synthane Coal Gasification

Three portions of the aqueous condensate from the U.S. Bureau of Mines Synthane coal gasification process were fractionated by the Stedman procedure. Ether was the extractant in the first two runs and methylene chloride was used in the third. The first test was carried out to get a feel for handling aqueous samples and backwashing of the extracts was not done; consequently, results of the first two experiments were not expected to check, and did not. Moreover, results from the methylene chloride experiment did not check well with the results from the second ether experiment. Carbon-14 labeled phenol was added in the latter two tests. In both cases, only about $70 \%$ of the label was recovered. In the ether extraction all of this phenol was found in the ether-soluble weak acid fraction, while in the methylene chloride extraction, about $85 \%$ of the recovered phenol was found in that same fraction and the remainder in the ether-soluble strong acid fraction.

Simulated In-Situ Retorted Shale Oil

Separation of the oil/water product was completed by batch centrifugation. Final yields were approximately: $27 \%$ water, $55 \%$ oil, and $18 \%$ oil/water/solid gelatinous phase. Some preliminary analyses of the neat aqueous phase, using GLC with a Tenax column, indicate monocarboxylic acids as major components. Phenol appears as a trace as well as many nitrogen containing compounds not yet identified. More thorough studies of neat aqueous samples are in progress and organic extracts are being prepared by several methods to obtain concentrates for trace component analyses. 
Whole samples of the shale oil and Synthane aqueous by-products have been submitted to collaborators in the Biology and Environmental Sciences Divisions for some mutagenicity and acute toxicity studies.

\subsection{Separation of Sulfur and Nitrogen Classes of Compounds from Complex Mixtures}

C. H. Ho and A. R. Jones

The production of fractions concentrated in sulfur and/or nitrogen components of a complex mixture is important in the analyses of these materials.

It has been reported that tobaces swike condensatc (TSC) may be separated into three distinct fractions on the basis of the metal-binding activity of ite components: (1) a noncomplexing fraction containing TSC. constituents which do not bind to metal ions, (2) protonated ligands containing those constituents of TSC able to form zero-charge chelates with metal ions, and (3) nonprotonated ligands forming complexes with metal ions. An attempt is being made to apply the rather poorly defined procedures to TSC and nonpetroleum-derived fuel oils to determine the extent to which sulfur- and nitrogen-containing substances may be concentrated.

A solution of $200 \mathrm{mg}$ of TSC in methyl isobutyl ketone (MIBK) was filtered through a 1- $\mu$ Fluoropore membrane and placed or a 2.5-cm-diam by $18-\mathrm{cm}-1$ ong column of carboxymethyl cellulose ( $\mathrm{Cu}^{\text {?t }}$ furm) which had been equilibrated with MIBK. Elution with that solvent washed a brown band through the column to give a yellow eluate. This solution was reduced in volume at $44^{\circ}$ and $40 \mathrm{~mm}$ pressure to $370 \mathrm{mg}$ of an amber oil which smelled of MIBK. A second brown band was eluted with $95 \%$ ethanol. This was concentrated to $95 \mathrm{mg}$ of amber oil of mild odor. All of the remaining dark material at the head of the column was then eluted as a yellow band. Some solvent evaporation yielded $3.117 \mathrm{~g}$ of slightly yellow wax with no odor.

The first material eluted is reported to be free of copper. The other fractions, which should be copper liganls, will be frccd of the metal, and all three will be examined by gas chromatography with S- and $\mathrm{N}$-specif1c detecturs. 


\subsection{Plant Microcosm Exposure Studies with Simulated Stack Gas Emissions}

A. D. Horton and B. R. Clark

Current studies involve the development of methods to introduce benzene and phenol into an air stream at a controlled rate.

Benzene delivery is accomplished using a glass bulb with an inlet extending to the bottom of the bulb and a vapor outlet at the top. The bulb is charged with benzene; nitrogen is bubbled through the benzene at various flow rates and collected in a gas trap cooled with dry ice. At $\mathrm{N}_{2}$ flows ranging from 7.1 to $96.8 \mathrm{ml} / \mathrm{min}$, all of the benzene vapor is collected in the first trap of a double trap arrangement. The production of benzene vapor vis fluw rate is nonlinear, ranging from $0.8 \mathrm{ml} / \mathrm{min}$ vaporized at $7.1 \mathrm{ml} \mathrm{N} 2 / \mathrm{min}$ to $10.1 \mathrm{ml} / \mathrm{min}$ vaporized at $96.8 \mathrm{ml} \mathrm{N} / \mathrm{min}$.

The projected air flow through the microcosm is 15 to $20 \mathrm{ft} 3 / \mathrm{min}$. Benzene vapor injected into the air stream at the above rates would produce a concentration range in the air of 1.9 to 23.7 Vppm at the $15 \mathrm{ft} 3 / \mathrm{min}$ rate, and 0.6 to $7.1 \mathrm{Vppm}$ at the $50 \mathrm{ft} / \mathrm{min}$ rate. The desired range of benzene concentration is $0.10 \mathrm{ppm}$. This same technique can be used for injecting other volatile liquids.

\subsection{Coal and Fly Ash Analysis by a Modified Multielement Isotope Dilution SSMS Technique \\ D. L. Donohue, J. C. Frank.lin, and J. A. Carter}

A technique has been developed for the analysis of up to 14 elements in coal and fly ash samples by spark source mass spectrometry. This involves the deposition of separated stable isotopes for the elements $\mathrm{Pb}, \mathrm{Tl}, \mathrm{Te}, \mathrm{Ba}, \mathrm{Cd}$, In, $\mathrm{Mo}, \mathrm{Sr}, \mathrm{Zn}, \mathrm{Cu}, \mathrm{Ni}, \mathrm{Fe}, \mathrm{Cr}$, and $\mathrm{Ca}$ from a solution onto high purity silver powder. This "spiked" silver can then be standardized to determine the true concentrations of the separated isotopes, as well as the "blank" level of normal isotopes for the same elements.

In the analysis of coal, the sample is ashed at $500^{\circ} \mathrm{C}$ in a muffle furnace, then homogenized on a Wig-L-Bug mixer. Fly ash samples are also homogenized in this way. A weighed amount of sample ash is then intimately mixed with a known amount of spiked silver powder, and formed into electrodes for sparking in the mass spectrometer.

Ion detection is by photographic plate, which is then read on a microdensitometer PDP-8/E system. Calculations of sample concentrations differ from standard isotope dilution work in that a sensitivity factor is necessary because the sample and spike isotopes do not reach chemical (only physical) equilibrium. Accuracy is established by using NBS SRM's 1632 (coal) and 1633 ( $f 1 \mathrm{l}$ ash). The precision is about 10\%. Advantages 
of this method include speed and simplicity of sample work-up with a minimum of chance for contamination. An additional advantage is that small samples can be analyzed (from 1 to $10 \mathrm{mg}$ of fly ash).

\subsection{Analytical Services}

W. K. Läing and L. J. Brady

A total of 177 samples were submitted for analysis during the month. Most of these samples were derived from solids-liquid separation tests. Samples that ranged in weight from 1 to $5 \mathrm{~g}$ were burned and the ash was found to be in the range from less than 0.1 to $10 \%$. 'I'he use of the new drying apparatus, which consists of eight intraired heat lamps with the heat output controlled by use of Variacs, resulted in a reduction of processing time and made it possible to report the results within two days from the time the samples were submitted for analyses.

A sample consisting of a mixture of methyl naphthalenes plus impurities was tested on the gas chromatograph. A simulated boiling range distribution test indicated that the boiling range was 224 to $262^{\circ} \mathrm{C}$. The mixture was found to be two parts 2 -methyl naphthalene to one part 1-methyl naphthalene. Four additional elution peaks were observed which together represented about $1 \%$ of the sample. These components were not identified chemically. 


\section{ENGINEERING EVALUATIONS OF THE SYNTHOII AND HYDROCARBONIZATION PROCESSES}

J. M. Holmes, R. Salmon, and E. G. St. Clair

Summary

Synthoil. Costs were obtained for most equipment items in the coal preparation section and a list of equipment power requirements was prepared. The flowsheet and overall material balance for a combined centrifugation-filtration plant were finalized. Process flow diagrams, heat and material balances, and equipment lists were finalized for Units 13 and 15. Minor changes were made to computer codes for calculating material balances for gasification and low-temperature carbonization, and work continued on listing and sizing equipment for these two sections. Compilation of utilities requirements for the overall facility indicate that a low-Btu gas production facility using additional fresh coal will be required.

Hydrocarbonization. The design and cost estimate for the coal beneficiation system was completed by McNally-Pittsburg Corporation and the final report was received. A cost estimate for the hydrogen preparation plant was received from C\&I/Girdler Incorporated. Vessels for the hydrocarbonization system were designed and costs are now being estimated. A computer code was developed for the design and costing of the DEA scrubbing systems for $\mathrm{H}_{2} \mathrm{~S}$ and $\mathrm{CO}_{2}$. removal. Equipment lists were prepared for the DEA acid gas removal plant (Unit 13) and the filtration plant (Unit 19). A preliminary flowsheet and a layout plan for coal and limestone preparation were prepared.

\subsection{Synthoil Process}

R. Salmon, E. G. St. Clair, M. S. Edwards, W. C. Ulrich, and D. A. Dyslin

Process flow diagrams, heat and material balances, and equipment lists were finalized for Unit 13, recycle gas and fuel gas treating (DEA), and Unit 15, low-temperature co shift feed-gas treating.

Preliminary utilities requirements for the overall synthoil facility were compiled. It appears that fuel gas production within the facility is not adequate to supply heat, steam, and power requirements, and that a low-Btu gas facility using additional fresh coal will therefore be required.

Work on various sections of the flowsheet progressed as follows:

(1) Coal Handling and Preparation: Costs were obtained for most equipment items in the coal preparation section, and a list of power requirements was prepared. 
(2) Gasification: The gasifier material balance was revised to account for a change in the moisture content of the coal feed. Work continued on listing and sizing equipment for the unit.

(3) Low-Temperature Carbonization: Paul M. Yavorsky of the Pittsburgh Energy Research Center (PERC) visited ORNL and talked with members of the evaluation project about the Synthoil process. One result of this discussion was a revision to the computer code for calculating the carbonizer material balance. The change gives a liquid recovery rate from carbonization of the solid-liquid separation residue more nearly representative of that predicted by PERC for this operation. Work continued on listing and sizing equipment, and a preliminary plot plan of the unit was prepared.

(4) Solids-Iiquid Separation: The flowsheet and overall material balance for a combined centrifugation-filtration plant were finalized. Equipment sizing is underway.

\subsection{Hydrocarbonization Process}

J. M. Holmes, D. S. Joy, G. R. Peterson, M. S. Edwards, C. B. Smith, and D. A. Dyslin

The designing and cost estimating of major equipment items in the hydrocarbonization plant is continuing. The various sections of the flowsheet progressed as follows:

(1) Coal Handling and Preparation: A preliminary flowsheet and a layout plan for coal and limestone preparation were prepared. Reviewers questioned the use of a reclaim coal pile and gravity-feed active piles vs the use of stacker-reclaimers as proposed by the McNally-Pittsburg Company. Further study is being done on this question.

(2) Coal Beneficiation: The design and cost estimate for the coal beneficiation system prepared by McNally-Pittsburg Corporation was completed and the final report was received. A revision to the f'lowsheet is under preparation to include raw coal needed for the fluid bed combustion system which will not have to be beneficiated. This addition was made because of an improvement in the clean/low-grade ratio produced by beneficiation which reduced the amount of low-grade coal available for fluid bed combustion while maintaining a constant feed of clean coal to the hydrocarbonizers.

(3) Hydrocarbonization: Vessels for the hydrocarbonization system were designed and costs are now being estimated. The process design and analysis (PDA) computer code is being used for sizing of the columns, compressors, heat exchangers, and pumps. A decision was made to include. a chiller on the hydrocarbonizer recycle stream to reduce the losses of naphtha in the stream as it is reheated by the fluid bed combustor. 
(4) Acid Gas Removal: Information was received from the Benfield Corporation concerning the design and cost estimation of two $\mathrm{CO}_{2}$ removal plants. A PDA computer code was developed for the design and costing of the DEA scrubbing systems for $\mathrm{H}_{2} \mathrm{~S}$ and $\mathrm{CO}_{2}$ removal. The DEA acid gas removal plant (Unit 13) equipment was sized, and utility requirements were estimated. Equipment lists were compiled for costing purposes.

(5) Hydrogen Preparation. Plant: A cost estimate for the hydrogen preparation plant was received from C\&I/Girdler Incorporated. The estimate also included process and utility consumption information.

(6) Oil-Solids Separation: The filtration plant (Unit 19) equipment was sized, and utility requirements were estimated. Equipment lists were also prepared. Capital cost for Unit 19 is estimated at \$9 million.

(7) Ammonia Recovery: A letter was written to Chevron Research providing specifications for ammonia and $\mathrm{H}_{2} \mathrm{~S}$ removal from the sour water. Chevron will furnish a conceptual design and cost estimate for this plant. 


\section{COAI-FUELED MIUS}

A. P. Fraas and W. R. Mixon

This project for analysis, design, and demonstration of a concept utilizing a fluidized-bed coal combustion system as a heat source for a gas turbine generator suitable for applications in Modular Integrated Utility Systems (MIUS) is carried out under the ORNL-HUD-MIUS Program within the Energy Division. Work is supported by the U.S. Department of Housing and Urban Development under HUD interagency Agreement No. 1AA-H-40-72 and by the Energy Research and Development Administration, Office of Fossil. Energy, under OCR contract No. 14-32-0001-1742. The. project consists of four phases: I - Conceptual Preliminary Evaluation; II - Conceptual Design; III - Detailed Design and Construction; and IV - Shakedown, Pert'ormance, and sindurance Tests.

\section{Summary}

The detailed design effort of Phase III and the preparation of a bid package for procurement of the fluidized bed furnace continued. An initial mixing test of coal injected into a fluidized bed was completed in the cold flow model and development of the vibrator-eductor coal feed system continued.

\section{Furnace Procurement}

The Combustion Engineering plant at Chattanooga was visited to discuss fabrication of the fluidized bed furnace. Results were most encouraging in that their facilities are more than adequate for the job, they have many of the required materials in stock, they can (and in fact prefer to) prepare the required shop drawings, and they are very interested in doing the job.

A package of drawings and specifications will be prepared as soon as possible and forwarded to vendors with a request for bids.

Turbine-Generator Unit

The progress of the turbine evaluation study was reviewed in a meeting with AiResearch on January 14. The aerodynamic performance and control studies have been completed. Analysis of the bearings and seals is continuing. 'lhere appears to be no aerodynamic or surge problems with closed cycle operation. A reference design speed of $75 \%$ of the full turbine speed was selected for use for the remainder of the study. A 6-module recuperator appears to be a better choice for the system than a 4-module unit, and the 6-module design will be emphasized in the rest of the study. 
Cold Flow Tests of a Fluidized Bed

An initial coal mixing test was completed by injecting coal at the lower center of the bed, running fluidizing air for short time intervals, and sampling the bed at four points at three levels. The fluidizing velocity for the test was slightly lower than the minimum operating velocity that had been selected from flow visualization tests. The results at 20 seconds showed good vertical mixing, but no horizontal mixing. After 40 seconds the coal distribution was uniform in the vertical direction but still very little horizontal mixing was found. The results after 80 seconds showed only a small amount of horizontal mixing. The results indicate that good vertical mixing, but essentially no horizontal mixing, will occur at very low fluidizing velocity. Additional. tests will be run at higher velocities to establish the mixing characteristics over the operating range of the fluidized bed.

\section{Coal Metering and Feed System}

Tests of the vibrator-eductor coal feeder system included measurements of the reproducibility of total feed rate and the feed rate of each of the four eductors. The total feed rate was about $500 \mathrm{lb} / \mathrm{hr}$ at the maximum setting on the vibrator and was reproducible to within about $5 \%$. The variation of flow among the four lines was about 15\%. Fine adjustment of the eductor nozzles was found to reduce this variation. Work will be continued to find the optimum setting for each of the eductors to obtain consistent flow rates with the minimum variation among the four lines. 
8. EXPERIMENTAL, ENGINEERING SUPPORT OF AN IN SITU GASIFICATION PROCESS

R. C. Forrester, III

\section{Summary}

Experimental work for this program was suspended in July to permit reassembly of the apparatus in an area which provides better containment of liquid and gaseous effluents and facilities more appropriate for associated clean-up operations. In the interim, analysis of data from early experimental work has been performed with the objective of revealing any preliminary implications of the first pyrolysis tests.

Scouting studies defining the effectiveruss uf aerosol dioengagement. techniques were continued under the immediate supervision of C. J. Golden, a summer employee presently completing requircmonte for the Mnster's degree in Chemical Engineering. Electrostatic precipitation and packed tower scrubbing (using water as the working fluid) were examined in detail, though only packed tower scrubbing appeared to be completely effective.

\subsection{Large-Block Pyrolysis Studies}

R. C. Forrester, III, P. R. Westmoreland, F. H. Wilson, and G. D. Owen

Work accomplished during the first third of FY 1976 has included the development of a computer code for rapid data analysis and an evaluation of the first thirteen pyrolysis experiments. These results were presented at the Second Underground Coal Gasification Working Group for Laboratory Research meeting at the Morgantown Energy kesearch Centcr, Ootobsr 16, 7975. Some of the calculational results have been transmitted directly to Jack Campbell of LLL for use in their kinetic model code.

As a result of funding delays, installation of the experiment in building 4505 was only completed in December with prclimiriary tests underway during the first week of January. These tests were successful and the generation of data has resumed.

\subsection{Coal-derived Aerosols: Disengagement Techniques}

C. J. Gulden, F. R. Westmoreland, and R. C. Forrester, III

As mentioned previously in earlier reports, rapid cooling of condensible organic vapors produced by pyrolysis of coal leads to the formatiun of aerosols which are extremely difficult to separate from the product gas stream. Such difficulties led us to conduct some quick scouting tests of traditional disengagement techniques with the objectives of improving the pyrolysis experiment and providing recommendations for others in the ORNL Coal Technology Program who might have aerosol disengagement problems. Qualitative Evaluations of systems tested to date are shown below. 
Table 8.1. Qualitative evaluation of some traditional disengagement techniques for trapping coal-derived aerosols

\begin{tabular}{ll}
\hline Technique & $\begin{array}{l}\text { Evaluation } \\
\text { and Comment }\end{array}$ \\
\hline Spray towers & ineffective $^{a}$ \\
Bubble columns & ineffective \\
Packed towers & very effective \\
Cartridge-type string filters & very effective \\
Electrostatic precipitation & partially effective \\
Glass wool demisters & partially effective \\
Internal cooling coils and glass wool & effective
\end{tabular}

ahese were one-stage devices using water as the working fluid. Repeat tests using a low vapor pressure organic solvent (such as methylnaphthalene) are planned. 


\section{THIS PAGE}

\section{WAS INTENTIONALLY LEFT BLANK}


ORNL/TM-5301

TITERNAL DISTRIBUTION
1. R. G. Affel
2. T. D. Anderson
3. S. I. Auerbach
4. J. K. Baird
5. R. E. Barker
6. H. C. Beeson
7. M. Bender
8. B. G. Blaylock
9. N. E. Bolton
10. R. E. Brooksbank
11. W. A. Bush
12. D. A. Canonico
13. R. S. Carlsmith
14. J. A. Carter
15. H. D. Cochran, Jr.
16. E. Copenhaver
17. I. T. Corbin
18. D. A. Creasia
19. W. K. Crowley
20. O. I. Culberson
21. F. L. Culler
22. J. E. Cunningham
23. V. A. DeCarlo
24. D. G. Doherty
25. A. S. Dworkin
26. M. S. Edwards
27. F. J. Endclman
28. G. G. Fee
29. D. E. Ferguson
30. L. M. Ferris
31. R. C. Forrester III
32. A. P. Fraas
33. W. Fulkerson
34. W. K. Gambill
35. D. A. Gardiner
36. C. W. Gehrs
37. J. B. Gibson
38. M. R. Guerin
39. C. W. Hancher
40. I. A. Harris
41. S. E. Herbes
42. S. G. Hildebrand
43. R. M. Hill
44. R. S. Holcomb
45. J. M. Holmes
46. R. B. Honea
47. J. K. Huffstetler
48. C. I. Hunt
49. T. J. Hurst

50. G. R. Jasny, $Y-12$

51. W. F. Johnson

52. L. L. Johnston

53. R. L. Jolley

54. J. E. Jones

55. D. S. Joy

56. S. Katz

57. O. I. Keller

58. R. F. Kimball

59. J. J. Kurtz

60. W. R. Laing

61. P. M. Lantz

62. R. S. Livingston

63. A. P. Malinauskas

64. G. B. Marrow, Y-12

65. W. R. Martin

66. W. J. McDowell

67. C. J. McHargue

68. J. R. McWherter

69-71. W.'R. Mixon

72. G. E. Moore

73. J. E. Mrochek

74. P. Nettesheim

75-84. J. P. Nichols

85. L. C. Oakes

86. G. R. Peterson

87-88. 'I'. W. Pickel

89. W. W. Pitt

90. H. Postma

91. J: J. Prislinger

92. W. T. Rainey

93. D. E. Reichle

94. C. R. Richmond

95. B. R. Rodgers

96-97. M. W. Rosenthal

98. W. I. Russell

99. Royes Salmon

100. R. W. Schede, Y-12

10I. C. D. Scott

102. A. J. Shor

103. D. S. Shriner

104. W. D. Shults

105. C. B. Smith

106. G. P. Smith

107. I. Spiewak

108. R. L. Spore

109. E. G. St. Clair

110. J. B. Storer

1.11. R. A. Strehlow 
112. O. K. Tallent

113. A. J. Thompson

114. D. B. Trauger

115. W. C. Ulrich

116. P. R. Vanstrum, $\mathrm{Y}-12$

117. J. S. Watson

118. J. R. Weir

119. P. R. Wcotmoreland

120. M. E. Whatley

121. J. C. White
122. M. K. Wilkinson

123. L. V. Wilson

124. R. G. Wymer

125. G. I. Yoder

126. C. S. Yust

127. Patent Office

128-132. Lab. Records

133. Trab. Records $-R C$

134-136. Central Research Library

137. Document Reference Section

EXTERNAL DISTRIBUTION

ERDA, Oak Ridge Operations

138. Research and Technical Support Division

ERDA, Washington

139. D. Ballantine, DBER

140. J. D. Batchelor, FE (Fossil Energy)

153. G. A. Mills, FE

141. T. Beresovski, DRRD

154. W. E. Mott, DBER

142. E. L. Clark, FE

155. M. B. Neuworth, FE

143. N. F. Cochran, FE

156. E. S. Pierce, DPR

144. C. W. Edington, DBER

157. H. E. Podall, FE

145. R. Franklin, DBER

158. J. L. Powell, FE

146. S. W. Gouse, FE

159. Robert Rabin, DBER

147. W. S. Harmon, FE

160. E. Schmetz, FE

148. G. E. Larson, $F E$

161. G. Stapleton, DBER

149. T. K. Lau, FE

162. R. E. Vener, $\mathrm{FE}$

150. R. W. A. LeGassie, AA/PA

163. H. Wasson, DBER

151. J. I. Liverman, AA/ES

164. P. C. White, AA/FE

1.52. C. Miller, FE

165. R. L. Zahradnik

Department of Housing and Urban Development, 4517 th street, s.W.,

Washington, D.C. 20410

166. G. S. Leighton

167. J. H. Rothenberg

National Science Foundation, 1800 G Slreel, N.W., Washington, D.C. 20550

168. R. S. Goor

169. Charles Johnson

Resource Planning Associates, Inc., 44 Brattle St., Ciubridge, Mass. 02138

170. hobert liea

U.S. Environmental Protection Agency, ETRL, 1055 Laidlaw,

Cincinnati, Ohio 45237

171. William E. Pepelko

U.S. Environmental Protection Agency, Research Triangle Park, N.C. 27711

172. Charles B. Sedman 
U.S. Steel Corp. Applied Research Laboratory, 125 Jamison Lane, Monroeville, Pa. 15146

173. N. S. Boodman, Section Supervisor

University of Kentucky, Institute for Mining and Materials Research, 213 Bradley Hall, Lexington, Kentucky 40506

174. Theresa Wiley, Institute Librarian

175. 0. J. Haun

176. J. K. Shou

177-188. ERDA Pittsburgh Energy Research Center, U.S. Energy Research and Development Administration, Attention: Director for J. P. Barreca, 4800 Forbes Ave., Pittsburgh, Pa. 15213

189-194. The Director, Morgantown Energy Research Center, P. 0. Box 800, Morgantown, West Virginia 26506

195. Jet Propulsion Laboratory, Attn: Library Acquisitions, 4800 Oak Grove Drive, Pasadena, California 91103

196. A. K. Ingberman, I Penn Plaza, Union Carbide Corporation, New York, New York 10001

197. D. E. Eissenberg, Union Carbide Corp., 270 Park Ave., New York, N.Y. 10017

198. R. E. Davis, Kerr-McGee Technical Center, P. O. Box 25861, Oklahoma City, Oklahoma 73125

199. H. Beuther, Gulf Research and Development Company, P.O. Drawer 2038, Pittsburgh, Pa. 15230

200. Robert Hangebrauck, National Environmental Research Center, Research Triangle Park, North Carolina 27717

201. P. H. Given, Pennsylvania State University, College of Earth and Mineral Sciences, University Park, Pa. 16802

202. John W. Larson, Department of Chemistry, University of . Tennessee, Knoxville, Tenn. 37916

203. Wendall H. Wiser, University of Utah, Department of Mineral Engineering, Salt Lake City, Utah 84112

204. William A. Peters, Massachusetts Institute of Technology, Department of Chemical Engineering, Cambridge, Mass. 02139

205. Donald Hanson, University of California, Department of Chemical Engineering, Berkeley, Callfornia 94720

206. S. G. Weilborn, Manager, Feedstocks Development, E. I. du Pont de Nemours \& Company, Inc., Wilmington, Delaware 19898

207. Tetra Tech, Inc., 1911 N. Ft. Myer Drive, Suite 601, Arlington, Virginia 22209, Attention: Walter McGough, Jr.

208-209. Jack Gillespie, UCCND, P. O. Box 1410, Paducah, Kv. 42001

210. Jerry D. Kennedy, Sandia Laboratories, P. O. Box 5800, Albuquerque, New Mexico 87115

211-237. Technical Information Center, ERDA, ORO 